\title{
PROEJA: A MATEMÁTICA CRÍTICA, OS SABERES DOCENTES PELO VIÉS DO PROJETO INTEGRADOR
}

\author{
Maria da Glória Medici de Oliveira1, Maria Auxiliadora Vilela Paiva²
}

\author{
Programa de Pós-graduação em Educação em Ciências e Matemática \\ Instituto Federal do Espírito Santo - Campus Vitória \\ Avenida Vitória, 1729 - Jucutuquara, Vitória, Espírito Santo. CEP 29040780.
}

\begin{abstract}
RESUMO
A pesquisa qualitativa, do tipo estudo de caso, produzida a partir da observação do cotidiano da sala de aula, objetivou estudar o ensino de Matemática Crítica e os saberes docentes no contexto do Cursos Técnicos Integrados ao Ensino Médio para Jovens e Adultos - PROEJA e do Projeto Integrador. A expectativa gerada em torno da pesquisa foi no sentido de construir um novo olhar para a formação do professor que atua no Proeja do Ifes - Campus Vitória do Estado do Espírito Santo, a partir de uma reflexão sobre suas práticas e os saberes por eles disponibilizados, tendo como referência as aulas de Matemática e de Projeto Integrador, numa perspectiva crítica.
\end{abstract}

Palavras-Chave: matemática crítica; saberes docentes; Proeja; projeto integrador.

\begin{abstract}
A qualitative research study of the type of case was produced from observation of everyday classroom, aimed to study the teaching of Critical Mathematics and teaching knowledge in the context of "Integrated Technical Courses in High School for Youth and Adults - PROEJA" and Project Integrator. The expectations generated around the research was to construct a new look for the training of the teacher who serves on the "PROEJA" - Federal Institute of Espírito Santo State, from a reflection on their practices and knowledge available for them, with reference to mathematics classes and Project Integrator, a critical perspective.
\end{abstract}

Keywords: critical mathematics; teaching knowledge; Proeja; integration project.

\footnotetext{
${ }^{1}$ Professora de Filosofia, Mestre em Educação em Ciências e em Matemática. Rede Salesiana de Ensino, VitóriaES. E-mail: gloriamedici@uol.com.br

2 Professora de Matemática, Doutora em Matemática. Docente do Programa de Mestrado em Educação em Ciências e Matemática do Instituto Federal do Espírito Santo. E-mail: vilelapaiva@gmail.com
} 


\section{INTRODUÇÃO}

Lembrando Paulo Freire (1996, p.22), em sua obra Pedagogia da Autonomia, quando nos fala: "A reflexão crítica sobre a prática se torna uma exigência da relação Teoria/Prática sem a qual a teoria pode ir virando blablablá e a prática, ativismo", foi que nos alertamos para os acontecimentos em sala, quando das aulas de Projeto Integrador ${ }^{3}$ e Matemática. Por isso, e por vários outros motivos, iniciamos nossa pesquisa com o nome de "Uma experiência única...", única porque o que foi se estabelecendo no decorrer do semestre mereceu atenção especial.

Diante da experiência com a proposta do Projeto Integrador, no PROEJA -Ifes Vitória, foi possível perceber a relevância do mesmo para desenvolver a autonomia do sujeito nessa modalidade de ensino. Considerando que temos um público com trajetória de exclusão e evasão da escola em período regular, o interesse cresceu na medida em que constatamos ser possível o trabalho interdisciplinar, na disciplina de Metodologia, responsável pelo desenvolvimento do Projeto Integrador, quando a mesma contribui no trato com outras disciplinas anteriormente consideradas assustadoras, para esse grupo específico. D’Ambrosio (2011, p.76) vem confirmar nossa inquietude diante da questão do conhecimento compartilhado e separado, afirmando que "a complexidade do problema do conhecimento deriva-se do fato de que é impossível separar as suas várias dimensões, assim como é impossível estudar fragmentadamente sua elaboração"

Nesse contexto, do PROEJA - Ifes campus Vitória, foi pensado esse projeto, uma vez que pesquisar os saberes docentes na construção do Projeto Integrador, será objeto de interesse para o desenvolvimento desse trabalho, saberes esses encontrados em todo lugar (SKOVSMOSE, 2007). Para isso, contaremos com o apoio dos professores de Matemática especificamente e dos alunos em questão, constituindo-se apenas os professores de

\footnotetext{
${ }^{3}$ Projeto Integrador: se constituiu em um componente curricular diferente dos demais, por não apresentar em sua estrutura um conteúdo prescrito ou, a priori, como as demais disciplinas que compõem a proposta curricular dos alunos dos Cursos Técnicos Integrados ao Ensino Médio para Jovens e Adultos do Proeja. Os conteúdos ou temáticas a serem desenvolvidas surgem a partir da discussão sobre as vivências, experiências e saberes dos alunos, ou seja, são oriundos da prática social na qual estão inseridos, seja ela entendida como o mundo do trabalho, o universo familiar, religioso, cultural e escolar. É a partir da problematização e da reflexão dessa realidade que esses educandos, orientados pelos professores, escolhem um tema para desenvolverem durante os três módulos do curso constituindo, dessa forma, uma unidade entre a teoria e a prática.
} 
Matemática e de Projeto Integrador como sujeitos da pesquisa. Para sustentar as informações, foi realizado um questionário misto, ou seja, com perguntas abertas e perguntas fechadas (TRIVIÑOS,1987), proporcionando o conhecimento do perfil dos sujeitos da pesquisa, com um aprofundamento maior em algumas respostas

Estabelecido como princípio o entendimento dos saberes que os professores utilizam para desenvolverem o Projeto Integrador, elegemos, como pano de fundo da pesquisa, as aulas que discutiram e desenvolveram sua metodologia de trabalho, juntamente com a disciplina de Matemática. É possível buscar a clareza da integração num momento em que essas disciplinas travaram uma rede de diálogo para o desenvolvimento do mesmo. Segundo Charlot (2005, p.38),

o sujeito se constrói pela apropriação de um patrimônio humano, pela mediação do outro, e a história do sujeito é também a das formas de atividade e de tipos de objetos suscetíveis de satisfazerem o desejo, de produzirem prazer, de fazerem sentido.

Logo, podemos afirmar que apropriar-se do patrimônio humano, ou seja, do conhecimento, implica para o sujeito apreender aquilo que está disponível em todos os sentidos, em todos os lugares, em todas as dimensões. Entendemos que é preciso que se estabeleça a integração, sendo necessário compreender o espaço da sala de aula, onde se desenvolve a relação dialógica entre os saberes do professor, na perspectiva do Projeto Integrador e da Matemática, visando contribuir na formação do professor e nas mudanças necessárias à melhoria da relação com esses saberes, numa perspectiva crítica.

Quando discutimos, na formação do professor, seus saberes, acreditamos abrir mais um espaço que facilite o ensino- aprendizagem da Matemática, desmistificando-a por meio da experiência do aluno. Para tanto, buscamos nos referendar em nomes que trazem uma discussão interessante nessa modalidade, provocando transformações no campo da Educação de Jovens e Adultos. Nossas bases estão sedimentadas em autores como Paulo Freire, e sua Pedagogia da Autonomia; Bernard Charlot, com a discussão da relação com o saber na formação de professores; Ubiratan D’Ambrosio trazendo à luz do debate o papel da educação numa sociedade em transição e Ole Skovsmose e sua proposta de uma Matemática Crítica que favoreça a aprendizagem matemática. 
Na perspectiva crítica direcionamos as observações da sala de aula, procurando o viés dos pensadores presentes nesse trabalho, para que, após uma análise detalhada, pudéssemos sugerir alternativas que atendessem ao princípio de uma educação para adultos há muito excluídos, utilizando para isso o Projeto Integrador do curso de Edificações, do Proeja-Ifes Vitória.

A discussão dos dados está limitada ao que até o presente momento foi possível coletar, pois pretendemos avançar além do apresentado nesse recorte, acreditando na pertinência de maiores informações que poderão, num trabalho futuro, complementar as conclusões até aqui analisadas. Nossa proposta inicial, portanto, foi a preocupação de aprimorarmos as bases teóricas apontando o que há de relevante para nossa pesquisa. Por exemplo, a opção que tomamos por Charlot (2005,p.91) está calcada em uma de suas idéias que nos indica que:

O ensino é transmissão de um saber, mas se essa transmissão pode tomar uma via direta, a via magistral, ela pode também se operar pela via indireta, aquela da construção do saber pelo aluno... o papel do professor como sendo menos o de comunicar seu saber que o de acompanhar a atividade do aluno, de lhe propor uma situação potencialmente rica.

Essa crença de que o protagonismo do aluno deve ser reconhecido no espaço da Eja, se remete ao fato de que eles trazem consigo uma experiência empírica rica em detalhes e sabedoria, o que vem no sentido de auxiliar o professor, quando o mesmo se encontra aberto à assimilação de novos saberes, se colocando numa relação que permite a construção de novos conhecimentos. Aliás, esse fato já pode ser comprovado a partir das observações realizadas em campo, durante uma aula de Matemática, quando um aluno $\mathrm{H}$ se reporta ao professor, nos estudos sobre porcentagem, dizendo que de alguma maneira ele fazia aquilo que o professor acabara de explicar, ao calcular semanalmente a quantidade de gasolina gasta num tempo determinado, para percorrer uma distância X. Essa foi somente a primeira participação, pois imediatamente outros alunos também correlacionaram suas ações e vivências, na área profissional. Destacaria Charlot (2000) a importância do papel do professor na lógica da pesquisa, sendo ele um sujeito voltado para o estudo das relações com o saber ou com o aprender. Mais que acumular conteúdo, o olhar do pesquisador-professor deve ir além do saber-objeto e, mesmo, da escola. 
Em se tratando de discussão de jovens e adultos, um nome se faz necessário, senão tornam-se em vão todas as argumentações utilizadas, estamos chamando Paulo Freire para a discussão. Freire (1996, p.23) apresentou sua fundamentação sobre o ensinar e o aprender, dizia ele: “Quem ensina aprende ao ensinar e quem aprende ensina ao aprender. Quem ensina, ensina alguma coisa a alguém... Ensinar inexiste sem aprender e vice-versa..." Ao processar a idéia freireana, entendemos e acordamos no sentido de que nossa pesquisa tem muito a coletar sobre o ensino e a aprendizagem numa sala de adultos e trabalhadores. Com esse olhar nos debruçamos nas práticas do ensinar trazidas pelo professor, e como essas práticas possibilitam e facilitam uma aprendizagem mais segura e verdadeira, diria até uma aprendizagem significativa. Em entrevista com o professor de Matemática, sujeito da pesquisa, ele citou algumas situações onde seus exemplos foram substituídos por exemplos trazidos pelo aluno, facilitando assim o entendimento do raciocínio pretendido, e mais que isso, dando significado àquilo que se discutia em sala de aula. Partindo então para o significado da aprendizagem e do conhecimento, vamos recorrer a Ubiratan D’Ambrosio (1996, p.18), uma vez que valoriza, no processo do conhecimento, as manifestações dos conhecimentos do presente, do passado em direção ao futuro. Como observa ele:

Minhas reflexões sobre educação multicultural levaram-me a ver o ato de criação como o elemento mais importante em todo esse processo, como uma manifestação do presente na transição entre passado e futuro. Isto é, a aquisição e a elaboração do conhecimento se dão no presente, como resultado de todo um passado, individual e cultural, com vistas às estratégias de ação no presente projetando-se no futuro, desde o futuro imediato até o de mais longo prazo, assim modificando a realidade e incorporando a ela novos fatos...

A julgar que estamos centrados numa sala de aula de EJA, passado, presente e futuro estão lado a lado nessa discussão. Para D’Ambrosio (1996) existem várias maneiras diferentes de entendimentos, de explicações, de lidar com a realidade, enfim, nesse campo a diversidade é enorme, no entanto está sob os cuidados do professor a tarefa de gerenciar a multiculturalidade presente num único espaço. Ao remeter à educação matemática, esse autor nos previne sobre o rumo de uma educação utilitarista, fotografia de uma sociedade tecnológica. Por outro lado, propõem ao docente um desafio, ou seja, uma atitude mais voltada para o cotidiano, que seja dinâmico no seu programa, que este esteja relacionado aos problemas de hoje. Alcançando um equilíbrio naquilo que já é sabido e aquilo que se está por 
saber. É esse o ponto chave do aproveitamento do Projeto Integrador, na perspectiva das aulas de Matemática e a possível facilitação da aprendizagem matemática.

Seria essa a forma de desmistificar uma disciplina que outrora aterrorizava alunos excluídos da educação, não raras vezes por causa de uma Matemática assustadora, inalcançável, inatingível. Nesse sentido poderíamos indicar o viés do Projeto Integrador, como auxiliar para um equilíbrio esperado, pois estaria ofertando, por sua dinâmica, situações concretas e reais de resolver problemas. Reconhecendo a importância e a necessidade da Matemática, numa sociedade da informática, constatamos a bagagem de dificuldades que nossos alunos carregam quando questionados sobre essa disciplina. Quanto ao professor, esse por sua vez vem buscando alternativas para minimizar o problema, uma vez que percebe não poder colaborar com a manutenção de uma metodologia já fracassada anteriormente, pois estamos nos referindo à turma de EJA. Aqui vale lembrar, em determinada aula de observação, uma cena muito interessante que nos remete ao que estamos verificando. Estava o professor conduzindo o raciocínio dos alunos, esperando que os mesmos resolvessem um problema posto e, após várias tentativas consultando a turma sobre as possibilidades, uma aluna declaradamente irritada, pediu ao professor que fosse mais objetivo e apresentasse a solução final. Ora, tudo que o professor não queria era exatamente repetir o mesmo erro das metodologias anteriores, que vinham com questões e respostas prontas. Em sua argumentação ele falou qual era seu objetivo, mostrando que todo o burburinho, reclamado por ela e que por ora surgia na sala, era de extrema valia no processo de aprendizagem. Foi necessário uma conversa direta para que a aluna entendesse o que estava se passando nas aulas de Matemática.

Verificar uma Matemática em ação, segundo Skovsmose (2007), onde será possível lidar com possibilidades, variáveis, estimativas, enfim, com situações do cotidiano e nele atuar em prol das expectativas do educando, passa a ser mais significativo e eficiente para promover o interesse no processo do conhecimento. Esse é o momento de acrescentar outra situação de sala de aula, quando estavam estudando casas decimais, e percebendo a dificuldade de apreender o que estava sendo proposto, o professor lançou mão da analogia com o dinheiro, como exemplo. Logo surgiram vários exemplos, de situações vivenciadas e também as suposições de problemas, por exemplo, de supermercado. Uma aluna relatou sobre o troco que acaba ficando no caixa, por falta de notas ou moedas. Nesse momento estavam discutindo 
arredondamento. Outro aluno falou, em seguida, sobre o montante que o supermercado junta a partir desse troco que "fica" 4 . Aproveitando a oportunidade vários alunos fizeram pequenos comentários, justificando sua participação.

A Matemática discute a parte econômica sim, mas pode discutir também situações ou modelos sociais que carregam algum tipo de intenção, e que pode nos passar despercebidos, como por exemplo, o caso citado. Estamos falando dessa Matemática viva, que permeia nosso cotidiano, e com ela a possibilidade de agregar, na escola, outras discussões que aparentemente fogem da área de exatas. Nesse papel, o professor tem que se abrir à assimilação de novos saberes, de novas possibilidades. Skovsmose (2007, p.122) acredita que: "Ao falar em matemática em ação, estou me concentrando em ver como as concepções matemáticas são projetadas na realidade."

Poderíamos citar várias situações de sala de aula de Matemática, onde fosse possível comprovar o aproveitamento dos conhecimentos trazidos. No entanto, entendemos ser suficiente o que, por ora, apresentamos e vamos partir para a análise das aulas de Projeto Integrador. Primeira observação a ser feita e muito importante para o andamento da pesquisa, é acertar o conceito de Projeto Integrador no curso de Edificações. Como vimos anteriormente, tivemos a preocupação de, logo no início do nosso trabalho, esclarecer seu conceito. Porém, ao começarmos a observação, ficou evidente que estávamos falando de coisas diversas. Enquanto nossa experiência nos direcionava para um tipo de pensar o Projeto, nos deparamos com outra proposta, não menos interessante que a primeira. Daí a necessidade de maiores esclarecimentos.

Para a o curso de Edificações do Ifes Vitória, Projeto Integrador é uma disciplina que tem por base aplicar novos conhecimentos em uma casa modelo, onde todos os alunos são convidados a transformar em prática toda a teoria aprendida. Isso veio facilitar nosso olhar, trazendo a certeza de que a Matemática teria uma grande contribuição, fortalecendo sua importância, como também ele iria contribuir para uma discussão e construção mais crítica da Matemática. No entanto, em uma das entrevistas com o professor da disciplina, foi perguntado se o planejamento ocorria em conjunto com Projeto Integrador, e obtivemos uma negativa como

\footnotetext{
4 "Fica" é uma expressão que vem significar que deixamos por livre e espontânea vontade, quando na verdade, somo induzidos a deixar prá lá, pois são casas decimais que caíram em desuso, mas que aparecem nas contas escritas.
} 
resposta. Esse fato nos chama a atenção para a necessidade que temos, enquanto formadores, sobre a Educação como processo, vinculada e interagindo com todas as questões que envolvem o sujeito.

$\mathrm{Na}$ análise dos dados algumas conclusões foram claras, porém três delas ficaram em evidência e se transformaram em objeto de interesse para um trabalho futuro:

I. Por mais que traga incomodo para alguns alunos, o professor de Matemática deve sustentar sua intenção em referência a uma metodologia que seja diferente daquela que expulsou os mesmos alunos da escola, no tempo regular, e que prima pelo diálogo, ampliando o protagonismo do educando, na construção do seu saber;

II. Os saberes que o professor de Matemática lida em suas aulas, deve permiti-lo abrir espaço para o saber trazido pelos alunos, na sua maioria, profissionais em busca de qualificação exigida pelo mercado;

III. Como ficou constatado, as aulas de Matemática poderiam ter sido de maior valia se houvesse um planejamento conjunto com a disciplina do Projeto Integrador, pois a contribuição se dá de forma casual, nada mais que isso, sem a mínima intenção direcionada, apesar da rica possibilidade de ajuda mútua, incluindo o diálogo com o material didático em constante processo de reavaliação.

\section{CONSIDERACÕ̃ES FINAIS}

As proposições até aqui apontadas foram no sentido de colaborar o quanto antes com a disciplina de Matemática, haja vista ter ela uma dinâmica cuja necessidade se interliga diretamente com o curso em questão, Edificações. Naturalmente os dados poderão, num futuro, serem acrescidos devido o volume de problemas que se apresentam na Educação de Jovens e Adultos, quando da disciplina de Matemática. Acompanhar o professor da disciplina e provocar diálogos com as demais que circundam seu universo, acreditamos ser uma das possibilidades de melhorar o ensino-aprendizagem da Matemática no curso do Proeja. Essas provocações estão restritas ao Projeto Integrador por uma opção dessas pesquisadoras, pelo entendimento da importância do mesmo. No entanto, não pretendemos negar o diálogo com outras disciplinas, que poderão, da mesma forma, trazer suas colaborações ao processo de ensino-aprendizagem de uma Matemática Crítica. 
Ao pesquisar a EJA, e particularmente no Ifes, o PROEJA, nos colocamos abertos para todo e qualquer trabalho que venha agregar conhecimentos que facilitem a formação do professor, para lidar com esse público. Assim, concluímos apresentando no corpo desse artigo os principais teóricos que colaboraram para uma discussão sustentável do ponto de vista da Educação de Jovens e Adultos e, também, da Educação Matemática, esperando ao final provocar reflexões sustentáveis de propostas que ajudarão os saberes docentes nas relações com os educandos, ofertando mais e maiores possibilidades na formação de um sujeito crítico.

\section{REFERÊNCIAS}

CHARLOT, Bernard. Relação com o saber, formação dos professores e globalização. Porto Alegre, Artmed, 2005.

CHARLOT, Bernard. Da relação com o saber: elementos para uma teoria. Porto Alegre, Artes Médicas Sul, 2000.

D’AMBRÓSIO, Ubiratan. Educação para uma sociedade em transição. 2.ed. Natal, RN: EDUFRN, 2011.

D’AMBRÓSIO, Ubiratan. Educação matemática: da teoria à prática. Campinas, SP: Papirus, 1996.

FREIRE, Paulo. Pedagogia da autonomia. Rio de Janeiro: Paz e Terra, 1996.

GODOY, Arilda S. Introdução à pesquisa qualitativa e suas possibilidades. In: Revista de Administração de Empresas, v.35, n.2, Março/Abril. 1995a .

PAIVA, Maria Auxiliadora Vilela. O Grupo Colaborativo do GEMP como contexto de construção de saberes e de relação com os saberes. In: Cadernos de Pesquisa em Educação PPGE-UFES. 2011. V.17, n.35, pp. 161-193.

SKOVSMOSE, Ole. Educação crítica: incerteza, matemática, responsabilidade. Trad. Maria Aparecida Viggiane Bicudo. São Paulo: Cortêz, 2007.

TRIVIÑOS, Augusto Nibaldo. Introdução à Pesquisa em Ciências Sociais - A Pesquisa Qualitativa em Educação. São Paulo: Editora, 1987. 